\title{
Atenção: modalidades atencionais e a problematização do diagnóstico de TDAH ${ }^{1}$
}

\section{Attention: attentional modalities and the questioning of the diagnosis of ADHD}

\author{
Giovanna Marafon² \\ giovannamarafon@gmail.com \\ Cátia Regina Papadopoulos ${ }^{3}$ \\ catiapapadopoulos@yahoo.com.br
}

\section{Resumo}

Este artigo visa a discutir as modalidades atencionais socialmente privilegiadas como padrão normal. O diagnóstico de TDAH, geralmente seguido da prescrição do fármaco metilfenidato, tem se sustentado na patologização da atenção que não se exerce de forma contínua e focalizada. Problematizamos o caráter normativo e os efeitos medicalizantes que o diagnóstico acaba por incitar. Nosso interesse se volta para as mudanças nas modalidades atencionais em curso no contemporâneo. Analisamos a emergência de diferentes modalidades atencionais que privilegiam atenção, contendo distração e descontinuidade, não como patológicas ou deficitárias, mas como aquelas que podem contribuir para repensar os processos de aprendizagem.

Palavras-chave: Atenção, Modalidades atencionais, Aprendizagem, TDAH, Medicalização

\section{Abstract}

This article aims to discuss the attentional modalities socially privileged as normal pattern. The diagnosis of ADHD, usually followed by the prescription drug methylphenidate, has been sustained in pathologizing the attention that is not exercised in continuously and focused way. We problematize the normative and medicalized effects that diagnosis turns out to incite. Our interest is directed to attentional modalities in course in contemporary world. We analyze the emergence of different attentional modalities that favor attention containing dispersion and discontinuity, not as pathological or deficit, but as those that can contribute to rethink learning processes.

Keywords: Attention; Attentional modalities; Learning; ADHD; Medicalization

\footnotetext{
1 Uma versão preliminar deste artigo foi apresentada como trabalho completo no IV GRUPECI Seminário de Grupos de Pesquisa sobre Crianças e Infâncias, com a temática "Ética e diversidade na Pesquisa", em setembro de 2014, na Faculdade de Educação da Universidade Federal de Goiás.

2 Pós-doutoranda em Educação PUC-Rio.

${ }^{3}$ Doutoranda em Educação PUC-Rio.
} 


\section{Introdução}

Não podemos desprezar que as crianças que chegam à escola hoje não apresentam docilidade nos corpos e durabilidade de atenção (DE-NARDIN E SORDI, 2009). Também não podemos desprezar que, de acordo com a lógica cultural em que estamos inseridos, recebemos diariamente uma avalanche de informações, sem nem conseguirmos nos apropriar de metade delas, devido à hiperestimulação que sofremos. Por outro lado, as atividades pedagógicas privilegiam a focalização, que envolve também o estar quieto em algum lugar, imóvel, prestando atenção, ou seja, acredita-se que quanto menos estímulos externos o aluno tiver, mais eficaz será sua aprendizagem. O que temos percebido em nossas experiências de formação de professores na universidade é que tem se instalado um impasse entre o que se costuma ensinar e aprender nas leituras de psicologia do desenvolvimento e da aprendizagem, as demandas que o contexto atual faz à escola e os discursos que identificam cada vez mais transtornos nos corpos de crianças e adolescentes.

É nesse contexto que se tem desenvolvido e incrementado o diagnóstico de Transtorno do Déficit de Atenção com/sem Hiperatividade (TDAH). Para um dos teóricos entusiastas do TDAH, Barkley (2002), esse é basicamente um "transtorno de desenvolvimento do autocontrole que consiste em problemas com os períodos de atenção, com o controle do impulso e com o nível de atividade" (p. 35). Os principais sintomas descritos pelo autor são: não prestar atenção a detalhes ou cometer erros por descuido; ter dificuldade para se concentrar em tarefas e/ou jogos; não prestar atenção ao que lhe é dito; ter dificuldade em seguir regras e instruções e/ou não terminar o que começa; ser desorganizado com as tarefas e materiais; evitar atividades que exijam um esforço mental continuado; perder coisas importantes; distrair-se facilmente com coisas que não têm nada a ver com o que está fazendo; esquecer compromissos e tarefas; ficar remexendo as mãos e/ou os pés quando sentado; não parar sentado por muito tempo; pular, correr excessivamente em situações inadequadas, ou ter uma sensação interna de inquietude; ser muito barulhento para jogar ou se divertir; ser muito agitado; falar demais; responder às perguntas antes de terem sido terminadas; ter dificuldade de esperar a vez; intrometer-se em conversas ou jogos dos outros. Além disso, não conseguir apresentar comportamentos como: 
"sentar quieto, atender, escutar, obedecer, inibir um comportamento impulsivo, cooperar, organizar ações e seguir completamente as instruções" (BARKLEY, 2002, p. 107).

No entanto, segundo Caliman (2008), existe uma "polêmica internacional" envolvendo o diagnóstico de TDAH, pois houve um aumento do número de casos identificados com o suposto transtorno no meio infantil e adulto, o que certamente repercutiu nas prescrições de estimulantes, entre outros aspectos. Por consequência, isso contribuiu para alimentar o clima de suspeita e discussões acerca do diagnóstico.

Os dados que fundamentam o discurso da legitimação médica e biológica do TDAH vêm das pesquisas neurológicas e das funções cerebrais, dos estudos feitos com as tecnologias de imagem cerebral e da pesquisa molecular e genética. [...] Os paradoxos em torno do transtorno invadem a mídia mundial, que tem divulgado o TDAH como diagnosis du jour, boutique disorder, psychofad e a Ritalina como "pílula da obediência". (CALIMAN, 2008, p. 560)

Alguns pesquisadores que investigam e problematizam a questão do diagnóstico TDAH têm pautado seus discursos na ausência de uma análise crítica em torno dos sintomas que sustentam tal diagnóstico e de suas relações com os fenômenos que ocorrem na educação, além do contexto histórico-cultural que os determina. A consequência da ausência dessa reflexão e da atribuição de um olhar reducionista à questão tem contribuído significativamente para 0 aumento do número de crianças diagnosticadas com TDAH e consequentemente indicadas para o tratamento medicamentoso desse suposto transtorno.

Portanto, interessa-nos realizar a problematização do diagnóstico TDAH e, com ela, trazer à tona maneiras outras de se pensar a atenção e as contribuições do campo educacional para realizar essa crítica. Encontramos ressonância no pensamento de Michel Foucault, que afirmou a necessidade de um trabalho crítico sobre o presente, na forma de uma atitude, nas palavras do autor:

Por atitude, quero dizer um modo de relação que concerne à atualidade; uma escolha voluntária que é feita por alguns; enfim, uma maneira de pensar e de sentir, uma maneira também de agir e se conduzir que, tudo ao mesmo tempo, marca uma pertinência e se apresenta como uma tarefa. Um pouco, sem dúvida, como aquilo que os gregos chamavam de êthos. (FOUCAULT, 2005, p. 341-342) 
Essa atitude de crítica, que problematiza, que produz problema lá onde pareceria haver certezas incontestes, é um exercício e um modo de olhar. Temos feito essa escolha como modo de proceder: recusar o diagnóstico de TDAH como algo pronto, acabado, certo ou verdadeiro. Cabe-nos questionar a sua montagem, sob quais condições ele se mostra uma verdade e, assim, o que ele acaba por obscurecer ou relegar a um plano secundário. Com isso, queremos dizer que o destaque para a noção de suposto transtorno contribui para a invisibilidade da matéria de trabalho educacional que são as modalidades atencionais. Entendemos que, no estudo das modalidades atencionais, está a positivação da atenção, a ser compreendida para além da forma binária - tem versus não tem; atento versus desatento.

Dessa maneira, organizamos 0 artigo em três partes. Em um primeiro momento, buscaremos trazer um breve panorama do TDAH, mostrando a fragilidade desse diagnóstico. Interessa-nos também discutir o processo de medicalização infantil, que envolve a concepção de transtorno do déficit atencional, tendo por base de análise o artigo de Caliman (2008). Além disso propomos problematizar o TDAH, considerando a recente publicação de uma portaria da Secretaria de Saúde de São Paulo sobre cuidados com a prescrição do fármaco metilfenidato na rede pública.

No segundo momento, pretendemos analisar mais de perto 0 desenvolvimento da atenção na perspectiva da cognição inventiva, tal como vem sendo proposta por Kastrup (2004) e corroborada por De-Nardin e Sordi (2009), com a finalidade de perceber o quanto esse deslocamento na compreensão da atenção pode contribuir de maneira positiva para repensar a aprendizagem.

Na sequência, com o objetivo de salientar a importância de olharmos para as modalidades atencionais de uma forma não patologizante, mas encontrando sentido para um ensino adequado aos alunos, faremos uma breve análise da Política Nacional de Educação Especial na Perspectiva da Educação Inclusiva (BRASIL, 2008). E, cotejando as análises sobre as práticas atencionais realizadas por De-Nardin e Sordi (2009), traremos as contribuições de Fernandez (2012) sobre as modalidades atencionais, o que pode contribuir para a ampliação do conceito de atenção e situar diferentemente as nossas práticas de ensino e aprendizagem. 


\section{Um breve panorama sobre o (TDAH) e a medicalização do não aprender}

Segundo Caliman (2008), quando pensamos em dificuldade de aprendizagem associada à falta de atenção e agitação do aluno, logo pensamos no Transtorno de Déficit de Atenção e Hiperatividade/Impulsividade - TDAH - o qual, principalmente, a partir da década de 1990, ganhou relevo nos meios psiquiátricos, psicológicos, escolares, familiares e mídia. Tanto que a referida década é conhecida como a "década do cérebro", segundo Lakoff (2000, apud Caliman, 2008, p.560) e como o ápice dos estudos neurológicos sobre o déficit de atenção. Completando esse cenário, ainda no mesmo período, foi publicado o quarto volume do Manual Estatístico e Diagnóstico de Doenças Mentais - DSM IV ${ }^{4}$ (American Psychiatric Association [APA], 1994), que reconheceu o TDAH ${ }^{5}$ como tal e o aumento considerável do uso do cloridrato de metilfenidato, comercializado com os nomes de Ritalina (Laboratório Novartis) e Concerta (Laboratório Janssen) como forma de tratamento para o transtorno.

Em maio de 2013, foi lançada a quinta edição do citado manual em um congresso de psiquiatria, em São Francisco - EUA, corroborando o déficit de atenção com a apresentação, ou não, de hiperatividade/impulsividade como transtorno. No mesmo ano, começou a ser comercializado outro medicamento, tendo como princípio ativo a substância dimesilato de lisdexanfetamina, com nome comercial Venvanse (Laboratório Shire), recomendado para o mesmo fim dos anteriores. Cabe destacar que os três atuam diretamente como estimulantes do sistema nervoso central, do grupo das anfetaminas e, como qualquer droga, trazem consideráveis efeitos colaterais. Ressaltando que esses medicamentos são recomendados para crianças a partir dos sete anos de idade, que apresentem pelo menos nove sintomas do que é considerado desatenção e/ou

\footnotetext{
${ }^{4}$ No ano 2000, o DSM IV recebeu uma revisão textual e foi renomeado DSM-IV-TR.

5 Cabe assinalar que esse transtorno sofreu modificações em sua nomenclatura no decorrer da história. Datam de meados do século XIX as primeiras referências aos transtornos hipercinéticos na literatura médica, sendo que, na década de 1940, surgiu a nomenclatura "lesão cerebral mínima", tendo sido modificada na década de 1960 para "disfunção cerebral mínima", pois se percebeu que os sintomas apresentados pela síndrome não estavam relacionados a uma lesão propriamente dita, mas a uma disfunção das vias nervosas (BARKLEY, 2002). Com o avanço das pesquisas, a nomenclatura continuou sendo modificada para "Reação Hipercinética da Infância", no DSM-II; "Distúrbio do Déficit de Atenção", no DSM-III; "Distúrbio de Hiperatividade com Déficit de Atenção", no DSM-III-R; "Transtorno do Déficit de Atenção/Hiperatividade", no DSM-IV e que se manteve no DSM V (versão atual, sendo a referência em uso desde o seu lançamento em maio de 2013).
}

Revista Educação Online, n. 18, jan-mai 2015, p. 58-75 
seis sintomas de hiperatividade e três de impulsividade, de uma lista de 18 sintomas, que devem estar presentes durante pelo menos seis meses. Esses quesitos estão de acordo com o DSM IV (estabeleceu que os sintomas devem aparecer antes dos sete anos de idade) e o DSM V (estabeleceu que os sintomas devem aparecer antes dos 12 anos de idade) e são aplicados através do instrumento "Snap IV6".

No entanto, introduzindo elementos de discussão e questionamento nesse diagnóstico e visando a orientar a prescrição do fármaco metilfenidato na rede pública de saúde, a Secretaria Municipal de Saúde do Município de São Paulo regulamentou a portaria ํㅜ 986, em junho de 2014. Isso porque uma série de questões problemáticas decorre do diagnóstico TDAH e do fármaco a ele associado como medida terapêutica. É importante que o campo psicoeducacional conheça de perto essas questões. A exemplo da Ritalina, tornada um elemento quase familiar nos meios escolares, de acordo com o Relatório de 2009 da Agência Nacional de Vigilância Sanitária - Anvisa, o cloridrato de metilfenidato

é um estimulante central e simpaticomimético de ação indireta com ações e usos similares a dexanfetamina. É utilizado no tratamento do transtorno de déficit de atenção (TDAH), narcolepsia, assim como para desordens de hiperatividade em crianças. Observa-se que redução de apetite e insônia são os principais efeitos colaterais do metilfenidato. Destacam-se também dor abdominal e cefaleia. Esse princípio ativo se encontra classificado no anexo da Portaria 344/98 na lista A3 Lista das substâncias psicotrópicas. (BRASIL, 2010, p. 40)

Ainda segundo informações da Anvisa, o consumo mensal de metilfenidato ao longo de 2009 foi de pouco mais de 5.000 .000 de miligramas em janeiro, chegando a 20.000 .000 miligramas em outubro; voltando a cair em dezembro - o que sugere alguma relação com os meses letivos do ano, o que merece ser investigado. De todo modo, um crescimento significativo, que nos faz refletir sobre todo esse cenário patologizante, que conecta o não aprender ou não se comportar de forma considerada adequada com supostos problemas neurológicos.

\footnotetext{
6 Uma versão do instrumento, em português, pode ser encontrada em: <http://www.tdah.org.br/images/stories/site/pdf/snap-iv. pdf>. Acesso em: 15/03/2015.
} 
Portanto, a portaria da Secretaria de Saúde de São Paulo é um posicionamento de vanguarda no âmbito das políticas públicas, que começa a destoar de um viés até então dominante na compreensão do suposto transtorno da "atenção deficitária". Essa nova portaria estabeleceu um protocolo clínico e a diretriz terapêutica para administração do fármaco metilfenidato, ponderando que:

O tratamento farmacológico deve ser considerado somente depois de levantamento detalhado da história da criança ou jovem e avaliação por equipe multidisciplinar em Centro de Atenção Psicossocial (CAPS) Infantil ou serviços com vínculo com o SUS, combinado com intervenções terapêuticas de natureza psicossocial e de educação. (Portaria no 986 SP, 2014, p. 5)

Colocou em questão a maneira desigual dos métodos de avaliação para o diagnóstico (não existe um único instrumento) e, nesse sentido, normatizou que não mais seja utilizado o instrumento "Snap N" como critério diagnóstico, uma vez que esse instrumento já vem recebendo críticas contundentes e consistentes. Também optou por acompanhar (mas não se restringir) (a)os critérios da Classificação Internacional de Doenças, em sua 10ªv versão (CID-10), e do DSM IV-TR, não aderindo à questão etária presente no DSM V - 12 anos de idade - a qual parece ter proposto o alargamento do espectro de crianças possivelmente identificadas como tendo o suposto transtorno. Mas, sobretudo, disciplinou uma perspectiva clínica mais abrangente e contínua, que considere envolvimento dos pais no processo diagnóstico e consulta com os adultos envolvidos no cuidado da criança, tal como os professores. Dessa maneira, conforme citado, a portaria destacou também a importância de intervenções partindo da educação.

Observamos que esse cenário se descortina de uma maneira complexa, no qual vozes dominantes fazem prevalecer suas verdades, através de pesquisas científicas que ainda precisam avançar e, sobretudo, precisam considerar aspectos éticos da pesquisa e enfrentar os conflitos de interesses (devidos aos vínculos com a indústria farmacêutica). Mesmo assim, há uma heterogeneidade de compreensões, que precisam ser reportadas. Por isso, trazemos à tona a visão de pesquisas que têm operado no plano psicopedagógico/educacional. E assim o têm feito também como modo de questionamento dos processos de medicalização da vida e, especificamente, da medicalização da aprendizagem. 
Medicalização é um conceito que emergiu no final dos anos 1960, referindo-se à crescente apropriação dos modos de vida humana pela medicina (GAUDENZl; ORTEGA, 2012). Entre os autores que pensaram o conceito e ofereceram a ele críticas e perspectivas, podemos mencionar Ivan llich (que enfatizou o lado opressivo da cultura medicalizada ocidental e, em contrapartida, afirmou as ações de saúde autônomas e heterônomas) e Michel Foucault. Nos anos 1970, Michel Foucault conceituou o biopoder e a governamentalidade como modo de governo das condutas, de si e dos outros, e, conforme apreensão de Gaudenzi e Ortega (2012), a medicina oferecia "a matéria-prima das regras que devem orientar a vida moderna nas formas gerais de existência e do comportamento humano" (GAUDENZI; ORTEGA, 2012, p. 30). A partir da norma, a medicina se constitui como instância criadora de parâmetros comparativos de saúde e de vida, sendo o saber-poder que orienta comportamentos e define o que está dentro e o que está fora da norma, qualificando-os como normal e anormal. Assim se percebe a medicalização intimamente associada à normalização dos modos de vida. No entanto, Foucault não deixou de pensar a positividade do (bio)poder, sua eficácia produtiva e a criação de novas formas de vida livres, que também criam e instituem seus valores. Entre os autores que têm problematizado a medicalização, também cabe mencionar a contribuição de Peter Conrad, sociólogo estadunidense contemporâneo, que tem pensado como 0 processo de medicalização transforma aspectos próprios da vida em patologias, ampliando o espectro do que é considerado anormalidade, constrangendo o que seria tido como normal ou aceitável.

Embora percebamos o campo educacional aparentemente passivo diante dos discursos médicos e sofrendo efeitos da medicalização, especialmente dos comportamentos dos escolares e de suas aprendizagens, havendo escassa reflexão sobre o assunto, encontramos referências psicoeducacionais para subsidiar nossa investigação. Dessa maneira, podemos avançar nos estudos sobre o processo de desenvolvimento cognitivo e, especificamente, sobre a atenção.

\section{Do suposto TDAH para a atenção com outra qualidade cognitiva}


Seguindo a proposta de problematizar, fazer questões, levantamos as indagações: será a atenção um pré-requisito fundamental para a aprendizagem ou a atenção precisa ser aprendida? Será que uma atenção distraída é mesmo prejudicial ao aprendizado?

Buscando recolocar as questões acima, vamos analisar de maneira mais cuidadosa as diferenças entre distração e dispersão, assim como entre concentração e focalização, no que diz respeito a suas condições em uma mirada de outra qualidade cognitiva, a cognição inventiva (KASTRUP, 2004).

Como vimos anteriormente, o problema da atenção tem ocupado um espaço considerável nas discussões atuais, seja na área médica, psicológica, educacional, mídia, nas políticas públicas etc., principalmente, devido à forma como ela tem funcionado na contemporaneidade. Quando se pensa sobre 0 assunto, atualmente, "o primeiro aspecto que sobressai é uma acentuada dispersão, que resulta da mudança constante do foco da atenção" (KASTRUP, 2004, p. 7).

Alguns fatores que têm contribuído para a produção de uma atenção dispersa, apontados por Kastrup (2004) são: a velocidade e quantidade de informações que circulam na internet e celulares, além de imagens e textos veiculados pela mídia em todo tempo, o que provoca uma mudança constante no foco da atenção. Corroborando com a afirmação da autora, acrescentamos que as representações de tempo e espaço sofreram mudanças em função do uso das tecnologias de informação e comunicação, pois, em questões de segundos, uma considerável quantidade de informações circula entre as pessoas, e isso não significa necessariamente conhecimento ou pensamento, mas apenas uma incorporação de informações, que faz com que o indivíduo esteja "conectado" em várias direções - e, muitas vezes, desconectado do mundo.

Não somente as transformações tecnológicas, como o uso crescente das mídias digitais, têm contribuído com a possibilidade de mudanças nas demandas atencionais, mas também as transformações percebidas nas dinâmicas de relação com o trabalho e no meio familiar. Atualmente, as condições de trabalho são instáveis e, não raras vezes, precárias. $O$ tempo de permanência em um mesmo emprego, quando ele existe formalmente, não é tão prolongado ou, 
ainda, os indivíduos exercem suas funções profissionais em mais de um lugar, de maneira fragmentada. Experimentam, entre outras condições, a sensação de aceleração do tempo e excesso de tarefas. No âmbito familiar, as transformações são observadas nas suas configurações que antes eram, predominantemente, nucleares e pautadas por modelos tradicionais, tendo ampliado as possibilidades de combinações e, com isso, muitas vezes exigem reorganização de atribuições e responsabilidades.

De que maneira os vários espaços em que os indivíduos circulam e convivem, tais como escola, ambientes de trabalho, famílias etc., têm interpretado essa dispersão acentuada, que, muitas vezes, tem sido diagnosticada como transtorno de déficit de atenção? Na escola, por exemplo, a ideia hegemônica de aprendizagem é a seguinte: a criança não aprende porque não presta atenção, ou seja, para que haja aprendizagem, é preciso que haja primeiramente atenção e boa capacidade de concentração. Assim, de acordo com Kastrup (2004, p. 8):

A noção de déficit indica que subjaz aí um entendimento da atenção como marcada por um funcionamento binário: 0-1, atenção-desatenção. Tudo aquilo que escapa ao ato de prestar atenção fica alocado na rubrica do negativo, da falta, do déficit. Ao procurar fazer frente ao funcionamento da atenção que foge da tarefa, são igualmente consideradas indesejáveis a dispersão e a distração.

A autora afirma, entretanto, que dispersão e distração são fenômenos distintos. A primeira "consiste num repetido deslocamento do foco atencional, que impossibilita a concentração, a duração e a consistência da experiência" (KASTRUP, 2004, p. 8). No entanto, pensando a distração, Kastrup nos oferece um registro que comporta interessante positividade:

Um funcionamento onde a atenção vagueia, experimenta uma errância, fugindo do foco da tarefa para a qual é solicitado prestar atenção e indo na direção de um campo mais amplo, habitado por pensamentos fora de lugar, percepções sem finalidade, reminiscências vagas, objetos desfocados e ideias fluidas, que advêm do mundo interior ou exterior, mas que têm em comum o fato de serem refratárias ao apelo da tarefa em questão. (p. 8)

Por isso, é importante observar que um indivíduo distraído é alguém imensamente concentrado, mas, apesar dessa condição, sua atenção pode se encontrar em outro lugar. Dessa forma, ao reduzir a atenção ao ato de prestar atenção, identifica-se o processo de concentração ao de focalização. Todavia, um fenômeno não se sobrepõe ao outro, pois pode haver focalização sem 
concentração e também concentração sem foco. A primeira situação - prestar atenção - predomina em um regime cognitivo, que é o hegemônico na subjetividade contemporânea; enquanto a segunda situação, menos valorizada, é a que se revela fundamental a um processo de invenção (KASTRUP, 2004). Dessa maneira, enquanto o regime cognitivo dominante na subjetividade contemporânea visa à resposta e solução de problemas, é possível pensar outra qualidade para o processo cognitivo, a de aprendizagem inventiva, composta por problematização e busca de soluções.

Todo esse estudo sobre distração, dispersão, concentração e focalização situa-se na área das ciências cognitivas, na qual o tema da atenção tem ganhado novos relevos desde a década de 1990. O que se busca privilegiar não é o déficit ou a falta de atenção, mas uma cognição inventiva que, para acontecer, precisa ser aprendida. É importante salientar que há uma diferença entre a cognição espontânea e a inventiva. A primeira funciona de acordo com a atitude natural, e a segunda depende de cultivo. De-Nardin e Sordi (2009, p. 101) resumem esse processo da seguinte maneira:

Assim, se de um lado lidamos com um conceito atual de atenção que a define enquanto um elemento necessário para o reconhecimento da informação, de outro lado, encontramo-nos com os estudos da consciência que apontam para outra perspectiva: a atenção que emerge como um estado possível e necessário para a invenção é uma atenção que transita entre estados de atenção focalizada e atenção distraída, que se trata de constelação de experiências e práticas, muito mais que uma questão de fixação, de olhar ou de sujeito como espectador.

Dessa forma, podemos indagar: que tipo de atenção as práticas pedagógicas estão produzindo?

\section{Modalidades atencionais diferenciadas}

Uma questão que se impõe atualmente é como o professor lida com modalidades atencionais diferenciadas em sala de aula. É possível percebermos que práticas tradicionais de ensino conduzem a uma aprendizagem que valoriza a capacidade de solucionar problemas de maneira mecânica, tendo a atenção um papel no controle do comportamento e no desempenho de tarefas cognitivas apenas. Assim sendo, a atenção fica a serviço da aprendizagem, tendo como principal função a captação e busca de informação (Kastrup, 2004) e, quando não atende tal objetivo, é considerada deficitária. 
Nesse sentido, podemos fazer uma breve análise acerca do que propõe um importante documento norteador da educação no Brasil: a Política Nacional de Educação Especial na perspectiva da Educação Inclusiva (BRASIL, 2008). Retomando a positividade presente na Declaração de Salamanca (1994), a política brasileira de educação inclusiva adotou o conceito necessidades educacionais especiais, e nele estão compreendidas as situações de deficiência e também as assim nomeadas "dificuldades de aprendizagem". Dentre elas, a política nacional nomeou, ainda compondo as necessidades educacionais especiais, a condição de "transtornos funcionais específicos". Sem maiores descrições e/ou explicações, tais supostos transtornos se encontram exemplificados por: "dislexia, disortografia, disgrafia, discalculia, transtorno de atenção e hiperatividade, entre outros" (BRASIL, 2008, p. 15).

Dentro de nosso interesse de análise neste artigo, destacamos a pertinência da inclusão do suposto TDAH no rol de necessidades educacionais especiais. Inicialmente, pode causar estranhamento o termo "transtorno funcional específico", termo oriundo de uma visão de transtorno - foi incluído no DSM IV, entendido como um "obstáculo funcional" no plano das "habilidades secundárias" - atenção e comportamento - que acometeria especificamente a aprendizagem, cujo caráter seria supostamente intrínseco ao sujeito, muitas vezes atribuído a causas neurológicas, do funcionamento cerebral. Portanto, traz para o campo educacional uma concepção eminentemente biomédica e desconsidera os avanços dos estudos cognitivos da atenção, especialmente da aprendizagem da atenção.

Reconhecendo um vetor medicalizante na nomeação transtorno funcional específico, entendemos que é preciso ter cuidado com a identificação de situações em que os alunos apresentem dificuldades em suas aprendizagens. $O$ diagnóstico TDAH pode corresponder ao anseio de oferecer reconhecimento às dificuldades e promover atendimento educacional especializado aos alunos que necessitem um olhar diferenciado e práticas educacionais outras.

No entanto, para isso, constrói um crivo entre os que têm transtorno e os que não têm, ou seja, acaba por reproduzir uma concepção tradicional de educação e coloca em cena o prestar atenção e ficar concentrado como normas para estar em condição de aprendizagem escolar. Em outras palavras, podemos 
dizer que normaliza a atenção, tanto por tomá-la como norma, tendo como parâmetro a forma "prestar atenção", quanto por identificar como anormal o que escapa a essa forma. Assim, se a resolução que implementa a Política Nacional de Educação Especial visa a oferecer condições para a realização de práticas inclusivas no âmbito escolar, podemos dizer que o caminho para fazê-lo é o de uma resposta compensatória a um processo prévio que foi de exclusão, por excluir da normalidade aqueles que nela não se inserem. Nesse caso específico, os anormais passam a ser aqueles identificados como deficitários em atenção.

As práticas de inclusão, nessa mirada, desconectam-se de uma política que deveria atravessar a escola e os modos de fazer educação, resumindo-se a tentar trazer alguns alunos de volta à condição estabelecida como normal. Entretanto, se por inclusão entendermos a virtual possibilidade de desenvolver outro modo de organizar e realizar a educação escolar, então a atenção pode ser um elemento no jogo de funções cognitivas que se associa a concepções mais alargadas acerca da aprendizagem. E aqui convém retomar as diferenças quanto à atenção, pois, em uma prática que privilegia o diálogo, na qual o aluno é estimulado a criar problemas e pensar em soluções, em que existe espaço para o trânsito da atenção-desatenção-invenção, acontece o aprendizado de uma atenção que privilegia a cognição inventiva. Melhor dizendo, nas práticas tradicionais, a aprendizagem acontece de forma mecânica, sem mudanças no sistema e não suficiente para a invenção do novo. Já em uma prática pedagógica mais aberta, a oscilação entre focalização-distração-retorno ao objeto reforçando que não se trata de um retorno ao que era antes, mas um retorno transformado - possibilita a criação da novidade.

No relato da pesquisa realizada por De-Nardin e Sordi (2009), as autoras tecem uma reflexão sobre dois exemplos de observação de salas de aula do ensino fundamental, mostrando como as formas de práticas pedagógicas desenvolvidas podem ter conotações diferenciadas e conduzir o aprendizado, tanto para uma situação em que diferentes modos atencionais são valorizados, como privilegiar apenas o prestar atenção. Do relato organizado a partir de mais ou menos cem observações, dirigidas às relações aluno-professor-objeto do conhecimento, destacamos aqui um dos exemplos que se mostra 
particularmente esclarecedor para pensar outras relações cognitivas, de atenção, com o conhecimento e como partilha entre muitos.

$\mathrm{Na}$ situação em questão (DE-NARDIN; SORDI, 2009), depois de apresentar o desenho de um muro de tijolos sobre o qual se podia ver cinco pares de mãos, a professora fez a seguinte solicitação aos alunos: "Vamos imaginar que tem umas crianças escondidas atrás desse muro. Olhem as mãozinhas delas aqui. Eu quero saber quantas crianças estão escondidas. Mas, olhem só, isso não é suficiente. Eu quero saber como vocês pensaram pra descobrir isso". Eles responderam que havia cinco crianças atrás do muro e que haviam chegado àquela conclusão contando as mãos de dois em dois. Somente um aluno discordou da resposta dada pela maioria e comentou sua hipótese: que uma criança poderia estar segurando com uma mão só! Dessa forma, foi lançado um problema, ou seja, algo no desenho fez aquele aluno lançar uma problematização, com isso inventando um novo problema.

Naquele momento, a professora acolheu a problematização do aluno, acionou a sua própria capacidade criadora e promoveu a das crianças, improvisando um muro-cartolina e propondo a todos que fosse realizada a dramatização da hipótese levantada. A professora acolheu a perturbação que resultou em momentos de problematização, pois se deixou ser tocada pela novidade proposta por seu aluno, permitindo uma experiência significativa de pensar sobre o pensamento, trazida por uma das crianças.

Nesse exemplo de observação da pesquisa de De-Nardin e Sordi (2009), em que a professora acolheu a problematização do aluno, em diversas situações, o/a observador(a) percebeu, ele/a próprio/a, sua capacidade de se distrair de um foco atencional, permitindo que sua distração o/a fizesse encantarse com o que as crianças revelavam. "Tais revelações eram tomadas como um saber em construção e não como um déficit” (p. 104).

A professora observada estava buscando encontrar um vínculo entre o que o aluno havia dito e o que estava sendo discutido, além de proporcionar um espaço para que o próprio aluno o encontrasse também. Tal atitude revelou uma preocupação da professora em valorizar e aceitar o outro como autor, conhecendo-o. Fica evidente que, naquele espaço da sala de aula, "tanto o aluno quanto o professor movimentam-se entre o lugar de quem está aprendendo e o 
lugar de quem está ensinando" (DE-NARDIN; SORDI, 2009, p. 104 - grifos nossos). Outro ponto ressaltado pelas autoras e importante aqui, é que o modo de atuação do professor vai contribuir para se efetuar uma qualidade subjetiva: subjetividade inventiva ou subjetividade recognitiva.

Um modo mais inventivo se constitui de uma "atuação inventiva, para o exercício da problematização" (DE-NARDIN; SORDI, 2009, p. 104), no qual a atenção requerida precisa poder se "distrair". Por outro lado, na forma da subjetividade recognitiva, ainda dominante no trabalho escolar, tanto de alunos como de professores, constitui-se uma "atuação recognitiva", caracterizada pela tendência a tomar o mundo como dado, oferecendo informações próprias para serem apenas captadas, atividade para a qual não se exige mais do que uma atenção focalizada. Portanto, afirmam De-Nardin e Sordi (2009, p. 104):

A análise dos protocolos revela que as chances de cultivar uma atenção concentrada e aberta crescem muito quando o espaço pedagógico promove situações em que se exercita o pensar sobre o pensamento. Tal exercício mobiliza uma atenção aberta a experiências não recognitivas, de estranhamento, de problematização, novas e inéditas, que atuam num plano de forças e não no plano da recognição.

Dessa maneira, partindo da perspectiva empreendida por Kastrup (2004) sobre cognição inventiva e desenvolvida por De-Nardin e Sordi (2009), podemos pensar em uma ampliação do conceito de atenção, levando-o para além de somente prestar atenção em algo, atividades ou situações externas ou, ainda, como um processo único e homogêneo; mas caberia pensar a atenção como um processo que se movimenta em diferentes direções e, por isso, pode apresentarse funcionando de diferentes formas. E essa atenção não se dá em qualquer lugar e a qualquer tempo, sob quaisquer condições; pelo contrário, exige também um espaço, nesse caso que o espaço pedagógico seja planejado e projetado para ser experimentado como lugar em que se exercita o pensamento, em que o pensamento pode pensar como pensa. Em vez de espaço voltado à mera recognição, um espaço pedagógico direcionado à invenção.

Seguindo na mesma direção que as autoras citadas, Fernandéz (2012) ressalta que é preciso reconhecer que as modalidades atencionais estão mudando e que podem ser transformadas em ferramentas criativas no processo de ensino e aprendizagem, em vez de serem consideradas modalidades patológicas ou deficitárias. O que ocorre, segundo a mesma autora, é que o 
docente espera receber um aluno com uma atenção focalizada e contínua, ou seja, unidirecional, porém, na realidade, depara-se com uma criança ou jovem habituado a modalidades atencionais dispersas e descontínuas, ou melhor, multidirecionais. Sendo assim, Fernandéz (2012) afirma que:

Essas mudanças na atencionalidade (que estão atravessadas pelas reconfigurações das representações de tempo e espaço impulsionadas pelas novas tecnologias) podem trazer condições benéficas para o desenvolvimento da capacidade atencional, quando é oferecido um ambiente facilitador. Ao contrário, convertem-se em obstáculos ou impedimentos, quando encontram um "ambiente" que os considera inúteis ou patológicos (p. 125. grifos no original).

Em outras palavras, um ambiente que privilegie a emergência de novas modalidades atencionais, sustentando e direcionando a dispersão/ampliação, pode estimular o pensamento e o trabalho de autoria do aluno. Em contrapartida, um ambiente hostil à modalidade atencional multidirecional pode resultar em fragmentação atencional, inibindo a capacidade de autoria pensante.

\section{Considerações finais}

Através das discussões e reflexões propostas neste artigo, verificamos que existem outras vozes nos estudos na área das ciências cognitivas e que esses têm avançado, demonstrando que existem diferentes modalidades atencionais. Essa multiplicidade atencional pode não estar sendo suficientemente considerada nas práticas pedagógicas, pois a ideia hegemônica na escola, na família, no ambiente de trabalho é a de que se o indivíduo não tiver foco e for distraído, ele não é bem-sucedido. Reside nessa crença uma grande possibilidade de as pessoas virem a encontrar algum alento e pertencimento no tão propalado diagnóstico de TDAH. Inclusive, o uso do metilfenidato tem crescido consideravelmente também entre adultos que buscam um melhor rendimento no mundo dos negócios.

Nosso intuito foi pensar e reforçar a necessidade de colocar em tela a aprendizagem da atenção, algo que vem sendo discutido em produções no campo da psicologia, como aquelas das quais nos valemos, e que podem ter importantes ressonâncias nas práticas educacionais. Para isso, na escola, é preciso abrir espaço para a aprendizagem da atenção, criar um ambiente acolhedor para a cognição em sua qualidade inventiva e para a criação do novo. Constituem-se, assim, conteúdos e reflexões necessários na formação de 
professores, especialmente como um contraponto aos discursos medicalizantes e que têm contribuído para operar a normalização das condutas escolares.

Em vez de promover ideias do que falta ao professor e ao aluno na atualidade, pensam será mais enriquecedor trazer considerações críticas ao campo escolar e abrir espaços para conhecer produções em ciências cognitivas que dialogam com temas caros à educação, como aprendizagem, cognição e atenção. São temas que, de uma maneira ou de outra, subsidiam currículos, práticas escolares e noções de (dificuldades de) aprendizagem. É tempo de rever essas definições, se quisermos apostar em ações que sejam de fato inclusivas e inventivas, de modo que a aprendizagem seja constituída e permeada pelas diferentes modalidades atencionais.

\section{Referências bibliográficas}

BARKLEY, R.A. Transtorno de Déficit de Atenção/Hiperatividade. Porto Alegre: Artmed, 2002.

BRASIL. Declaração de Salamanca e linha de ação sobre necessidades educativas especiais. Brasilia: Unesco, 1994. Disponível em: $<$ http://portal.mec.gov.br/seesp/arquivos/pdf/salamanca.pdf $>$. Acesso em: 15/03/2015.

Política Nacional de Educação Especial na Perspectiva da Educação
Inclusiva. Brasilia: MEC/Seesp, 2008. Disponível em: $<$ http://portal.mec.gov.br/arquivos/pdf/politicaeducespecial.pdf>. Acesso em: 15 de março de 2015.

BRASIL. Agência Nacional de Vigilância Sanitária. Relatório de Atividades 2009/ Agência Nacional de Vigilância Sanitária. Brasilia: Anvisa, 2010.

CALIMAN, Luciana Vieira. O TDAH: entre as funções, disfunções e otimização da atenção. Psicologia em Estudo, v. 13, n. 3, p. 559-566, 2008.

A constituição sociomédica do "fato TDAH". Psicologia e

Sociedade, v. 21 n.1, p. 135-144, 2009.

De-NARDIN, Maria Helena; SORDI, Regina. Um estudo sobre as formas de atenção na sala de aula e suas implicações para a aprendizagem. Revista Psicologia e Sociedade, v.19, n.1, p. 99-106, jan-abr 2007.

Aprendizagem da atenção e os modos de subjetivação

pedagógica e informacional. Psicologia e Sociedade, v. 20, n.1, p. 53-61, 2008. Aprendizagem da atenção: uma abertura à invenção.

Revista Semestral da Associação Brasileira de Psicologia Escolar e Educacional (ABRAPEE), v. 13, n. 1, p. 97-106, 2009.

FERNANDEZ, Alicia. A atenção aprisionada: psicopedagogia da capacidade atencional. Porto Alegre: Penso, 2012.

FOUCAULT, Michel. "O que são as Luzes?". In: Ditos e Escritos II - Arqueologia das ciências e história dos sistemas de pensamento. Rio de Janeiro: Forense Universitária, 2005. 
GAUDENZI, Paula; ORTEGA, Francisco. O estatuto da medicalização e as interpretações de wan llich e Michel Foucault como ferramentas conceituais para o estudo da desmedicalização. Interface - comunicação, saúde, educação, v. 16, n. 40, p. 21-34, 2012.

KASTRUP, Virgínia. A aprendizagem da atenção na cognição inventiva. Psicologia e Sociedade, v.16, n.3, p. 7-16, set-dez 2004.

SECRETARIA DE SAÚDE DE SÃO PAULO. Portaria nำ986, de 12 de junho de 2014. Disponível em:

$<\mathrm{ftp}$ ://ttp.saude.sp.gov.br/ftpsessp/bibliote/informe_eletronico/2014/iels.jun.14/le Is110/M_PT-SMS-986_2014.pdf>. Acesso em: 15/03/2015. 